\title{
Desenvolvimento de resistência à insulina em equinos Mangalarga Marchador com a obesidade induzida
}

Rodrigo Martins Ribeiro", Debora da Silva Freitas Ribeiro, Cahue Francisco Rosa Paz, Davi Silveira Diniz Azevedo, Leticia Oliveira Cota, Antônio Catunda Pinho Neto, Rafael Resende Faleiros

Universidade Federal de Minas Gerais (UFMG), Belo Horizonte, MG, Brasil

*Autor correspondente

e-mail: vetrodrigo@msn.com

\section{Resumo}

A resistência à insulina (RI) é o ponto central dos mecanismos fisiopatológicos da síndrome metabólica equina (SME). A grande maioria dos cavalos e pôneis afetados apresenta o quadro de obesidade generalizada e/ou regional. As técnicas para diagnosticar a RI são de alto custo e complexas, dificultando o seu uso na rotina do clínico. A identificação de métodos mais acessíveis para serem utilizados na prática clínica é imprescindível para possibilitar intervenções precoces e uma melhor avaliação e acompanhamento dos animais com essa afecção. 0 objetivo deste experimento foi caracterizar as alterações no perfil hormonal em equinos submetidos à dieta hipercalórica, com a finalidade de verificar e conhecer melhor o desenvolvimento da resistência à insulina equina e tentar encontrar ferramentas que possibilitem a realização de seu diagnóstico precoce. Foram utilizados nove equinos Mangalarga Marchador adultos com escore corporal (EC) médio ( \pm DP) inicial de 2,9 \pm 1 (escala de 1-9), submetidos à dieta hipercalórica atingido um EC de 8,3 \pm 1 após 5 meses. Os dados foram coletados antes do início do experimento e com o intervalo de 15 dias até o final do experimento; os valores plasmáticos foram obtidos para mensuração das concentrações de frutosamina, glicose e insulina. Foram mensurados os proxies G:I, RISQI, HOMA-IR e o MIRG. Foi realizado o teste de baixa dose de glicose oral (TBDGO), utilizando a área total sob a curva de glicose (ATG) e insulina (ATI) em três momentos: antes da indução à obesidade, após 90 e após 150 dias. Os resultados foram submetidos à análise de variância considerando-se os efeitos de tempo, e as médias comparadas com medidas repetidas pelo teste de Tukey, com o valor $\mathrm{P} \leq 0,05$. A RI foi observada nos primeiros 90 dias de experimento, caracterizandose como um quadro de RI descompensada, apresentando um aumento dos níveis plasmáticos basais de glicose, frutosamina e insulina, pelas alterações em todos os proxies e com um aumento significativo da ATG $(\mathrm{P}<0,001)$ e ATI $(\mathrm{P}<0,05)$. Contudo, ficou evidente uma compensação do quadro de RI após 150 dias de experimento, sendo demonstrado pelos dados da resposta secretória insulínica das células $\beta$ do 
pâncreas, que se manifestou pelo aumento dos níveis plasmáticos de insulina pós-jejum ou exposição à glicose gástrica, com concomitante redução nos níveis de glicose e frutosamina pós-jejum, e pela redução da ATG e pela marcada elevação de ATI $(\mathrm{P}<0,0001)$ no teste dinâmico. Tais achados comprovam a ocorrência de hiperinsulinemia associada à resistência insulínica em equinos Mangalarga Marchador expostos à dieta hipercalórica.

Palavras-chave: Disfunção insulínica. Cavalo. Síndrome metabólica equina. 